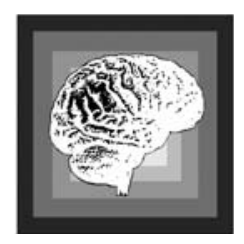

\title{
The making of 'American': race and nation in neurasthenic discourse
}

\author{
BRAD CAMPBELL* \\ California Polytechnic State University
}

\begin{abstract}
This paper considers the underexamined racial and nationalistic components of late nineteenth-and early twentieth-century neurasthenic discourse to propose that neurasthenia was as much a discourse of modern American identity as it was a discourse of disease. By closely reading the medical and general texts which helped to popularize it, and by scrutinizing the context of its vogue and supposed subsequent decline, this paper shows how neurasthenia was intimately bound up with the era's politics of race, nationalism and citizenship. Countering traditional understandings of the disease, this study suggests that neurasthenia did not simply anticipate but was pre-eminently preoccupied with the questions and crises of modernity; that it was not, after all, a quintessentially Victorian but a fundamentally modernist discourse, and a paradigmatic example of how the construction of a neurotic American subject was necessarily and inevitably a construction of a modern American subject.
\end{abstract}

Keywords: African-American; George Beard; insanity; nationalism; neurasthenia; race; USA

On or about November 1918, neurasthenia is supposed to have died. Of course, its death had been anticipated for some time, and more than a few observers had presaged (or at least hoped for) its demise much earlier. Charles L. Dana, for instance, an eminent neurologist and early convert to Freudian psychoanalysis, heralded the 'partial passing of neurasthenia' in his 1904 article with this title. For Dana, though, there was really nothing 'partial' about it. After meticulously thinning the disease's symptom catalogue by

\footnotetext{
* Address for correspondence: California Polytechnic State University, Department of English, Bldg. 47-32, San Luis Obispo, CA 93407, USA. Email: bcampb02@calpoly.edu
} 
'about 50\%', he proposes that 'if one follows it up very closely we may yet end in finding that there is no such thing as neurasthenia at all' (Dana, 1904: 341). Dana's conclusion was, for its time, perhaps too ambitious, but only slightly premature: by 1917 , Robert S. Carroll (1917: 23) could sense that the 'time [was] rapidly coming' when neurasthenia would fall from its cultural pedestal, and by 1921 Wade Wright could claim with confidence in the pages of Mental Hygiene that it was 'no longer the height of good form to enjoy poor health' (Lutz, 2001: 51) - a subtle dig at 'fashionable' neurasthenics and a telling suggestion that the era of neurasthenia had already ended.

Modern medical historians and other scholars of the disease have generally followed such texts when marking the historical perimeter of the malady. In Marijke Gijswijt-Hofstra's introduction to a brilliant collection of essays, Cultures of Neurasthenia, she observes that 'The First World War marked more or less the final retreat of neurasthenia' (Gijswijt-Hofstra and Porter, 2001: 1). Scholars past and present appear to agree, noting variously that the disease 'had been all but forgotten' (Gosling, 1987: 13), had 'all but disappeared' (Hyman, 1998: 8) or had 'effectively been demolished' (Sicherman, 1977: 36) somewhere around this time. Thus, by the advent of, or sometime during, World War I, but certainly by the end of the war, neurasthenia - the nineteenth-century's most fascinating and fashionable disease, its one time preoccupation, its 'king of neuroses' (Beard, 1880: 26) had apparently breathed its last.

It is surprising, then, to find that as late as the 1930 s, neurasthenia was still the topic of lively medical discussions and the cornerstone of a veritable and vibrant nervous illness market. It was still the (not-always-celebrated) subject of self-help books, medical and pseudo-medical treatises, novels and memoirs; still the life-blood of the country's various sanatoriums and health retreats; still a lucrative source of patients for private medical practice. Indeed, neurasthenia seems to have enjoyed a remarkable life after its supposed death. In a 1930 article which otherwise disparages the disease as a catch-all diagnosis for lazy doctors, A. A. Brill (1930: 124) nonetheless admits that 'neurasthenia is still very popular with the medical profession'. In fact, his article appeared in a special edition of the Medical Review of Reviews which included a preface by Freud and contained a 'Symposium on neurasthenia'. As Dorian Feigenbaum (1930), the issue's editor, explains, 'The subject of neurasthenia was chosen first, because the term is loosely used, and even abused, in medical diagnostics, and it is time to clear up our ideas on this subject and to come to some understanding of its meaning'. The passage clearly anticipates Brill's criticisms of the disease later in the symposium, but it tells us something more important about the status of the malady long after World War I: although certainly abused, neurasthenia was anything but dead, nor was it the purpose of this symposium to dismantle it. On the contrary, neurasthenia's meaning was still being negotiated, and there was hope, at least for Feigenbaum, that the disease, with all its singular and 
superior illustrations of the interdependence between somatic and psychic factors, would lead to a 'deeper understanding of the generally surmised ultimate somatic basis of neurotic phenomena'.

On the other side of the Atlantic, and in non-medical contexts, there were also signs that neurasthenia was alive and well. For instance, Doris Mary Armitage (1929: 17) lamented that, at least from a British perspective, neurasthenics were 'unhappily an increasingly large class of sufferers'. The steady publication of neurasthenic material in the USA and Europe would seem to support her observations, as books and pamphlets offering general information, advice or remedies for neurasthenia and related illnesses continued to 'pour off the presses' in the 1920s (Lutz, 2001: 59). Evidently, neurasthenia survived the war after all, and the reports of its death seem to have been greatly exaggerated.

My purpose here, however, is not to propose my own set of dates for the life-span of neurasthenia. I am, indeed, rather sceptical of the traditional markers of its rise and fall, and I suspect that saying this disease died some time around World War I - during that saturated segment of years at the feet of which we bury so many modes and movements - is largely a matter of convenience or habit. Seeing things this way allows us to examine neurasthenia as a closed system, but it also requires us to accept problematic historical elisions like the ones Rebecca Hyman (1998: 8) makes when she claims that George Beard 'discovered' the disease in 1869 (which he did not) and that it 'suddenly disappeared' decades later (which it did not). If neurasthenia is dead, it must be because we killed it - we have murdered to dissect, but at the expense of a more thorough and nuanced understanding of the disease, its history and the scope of its cultural work.

While the evidence above gives us reason to reconsider how and where we pinpoint its passing, it is less important to identify when neurasthenia died than it is to ask what this supposedly 'Victorian' disease bequeathed to the modern world from which it is supposed to have vanished. I would contend that this is not exclusively or even essentially a Victorian disease at all, but when we insist on the easy alignment of its death with the end of World War I, or claim that 'the lifespan of neurasthenia corresponds to the period of realism in American literature' (Lutz, 1991: 36), we implicitly accept that this disease was really just another late nineteenth-century phenomenon which, like so many other of that era's fads and fashions, crumbled under the pressures of modernism.

I would rather see neurasthenia as not simply a preface to American modernism, but to some degree constitutive of it, and in this paper I offer an interpretation of neurasthenia which reads it as a discourse of modern American identity as well as a discourse of disease - one which was intimately bound up with early twentieth-century politics of nationalism and citizenship. I begin by examining the emergence of neurasthenia in America ${ }^{1}$ in the nineteenth century, emphasizing George Beard's seminal contributions to 
its formation and popularization. I then consider neurasthenia in vogue, paying particular attention to the conditions of its popularity and the features of its crisis in the early part of the twentieth century. My primary purpose here will be to show that neurasthenia does not simply anticipate but is preeminently preoccupied with the questions and crises of modernity; that it is not, after all, a quintessentially Victorian but a fundamentally modernist discourse, and a paradigmatic example of how the construction of a neurotic American subject was necessarily and inevitably a construction of a modern American subject.

In the paper's final section, I turn to examine more closely the implications of this particular construction of 'American', asking how and why the prejudices of neurasthenic discourse and, more specifically, its racist assumptions, were so readily accepted and circulated in the early twentieth century. I suggest that one way to understand how the social logic of neurasthenia became so firmly entrenched is by considering it in light of the nineteenth-century's 'insanity question' - a question largely overlooked by historians of psychiatry and so far entirely unexamined as a context for and collaborator with neurasthenic discourse. By illuminating the features and functions of this question, I show how it inspired and conspired with neurasthenia to construct a relationship between race, nation and neurosis that would preoccupy writers on both sides of the colour line well into the twentieth century.

\section{The advent and ascent of 'the American disease'}

Although, despite his own claims to the contrary, George Beard did not coin the term 'neurasthenia', he was more than any other responsible for shepherding it towards international recognition and its status as a national preoccupation. ${ }^{2}$ By no means was he the only one writing about neurasthenia in the nineteenth century, but he was the first to popularize it deliberately - to see and articulate its value not simply for a specialized scientific audience, but a broadly national one as well. In Beard's American Nervousness (1881), popularity was the point, and while he claims that this presentation of neurasthenia was 'designed as a supplement' to his more narrowly scientific treatise on the disease the year before, he quickly acknowledges that it is 'of a more distinctly philosophical and popular character'. Indeed, Beard ranges so widely that readers may be apt to forget they are reading a work of neurology at all, containing as it does so many curious asides and manifold musings on everything from the American educational system to the 'phenomenal beauty of the American girl'. American Nervousness is, in short, a veritable index of the nation's ideas, attitudes, assumptions and prejudices which has its feet firmly planted in the nineteenth century but its eyes clearly fixed upon the twentieth. It was, if not the earliest, then certainly the most powerful and coherent articulation of national identity in terms of disease, and it would almost single-handedly bring the unlikely concept of neurasthenia into the mainstream of nineteenth-century America. 
That neurasthenia is as much an identity as a disease is evident almost from the beginning of American Nervousness. Beard's initial portrait of the neurasthenic highlights the 'fine, soft hair, delicate skin [and] nicely chiselled features' which distinguish this population of sufferers (Beard, 1881:26). We will not find here the 'thickness of the lip' or the irregular 'size of the nose' that marks the 'less refined' sort: the barbarians, the savages and, more curiously, the English when viewed up close (p. 69). On the contrary, neurasthenics are comparatively dainty, with 'small bones' and 'tapering extremities' (p. 26). They may have bad teeth, but this is a product of their sensitiveness and their whiteness: Indians and Negroes, Beard notes, 'suffer but little this way' (p. 49). Fortunately, neurasthenics can afford good dentists, for they are, not surprisingly, of the 'better sort': the 'in-door classes' or 'brain-workers' (p. 23), as Beard called them, 'the professional and business men of America' upon whom the country's success and progress depend (p. 23). Chances are that a neurasthenic is balding, for this is one of the 'minor but most instructive expressions of nerve sensitiveness', as well as a useful marker of whiteness, for '[a]mong savages in all parts of the earth baldness is unusual' (p. 52). If the neurasthenic happens to be a woman, she will not be balding, but she will almost inevitably be beautiful and weak - her indoor lifestyle robs her of the strength of 'the squaws' (p. 185), but it also keeps her pretty. A 'woman who works all day in the field', after all, 'is not likely to be very handsome, nor to be the mother of handsome daughters' (p. 67).

Neurasthenics also sound different, clipping their words because full enunciation 'makes severe draughts on time and force' (p. 85). For the same reason, neurasthenics are not dressed in bright, garish colours because 'higher culture and sensitive nerves react to slight irritation; while low culture and insensitive nerves require strong irritation. Loudness of dress is, therefore, justly regarded as proof of coarseness of nerve-fibre' (p. 74). Too much colour, in other words, taxes the neurasthenic's energy reserves.

The remaining features of neurasthenics are rather predictable: they are Protestant, for '[no] Catholic country is very nervous' (p. 126) and they primarily reside in the cities of the North, where nervous diseases are 'more frequent and more complex' (p. 159). They are also inveterate letter-writers, this activity being peculiarly 'American' and an 'index of nervousness' (p. 135) perhaps because it suggests a level of literacy one would naturally, in Beard's terms, associate with this class of sufferers.

What we must finally see in this scrupulous study of neurasthenic identity is that Beard, after all, was describing himself, along with the class of patients he saw and treated in his private New York neurological practice: white, wealthy, urban Northerners, primarily men ${ }^{3}$ of the brain-working class, men of the 'desk, the pulpit and ... the counting room' (p. 26), responsible for keeping the engine of civilization running. These individuals were the inevitable effect of a disease, the 'chief and primary' cause of which was, in Beard's aetiology, 'modern civilization' - a broad concept defined not just by the technological 
innovations of the nineteenth century, 'steam-power, the periodical press, the telegraph, the sciences', but by social ones as well: 'the mental activity of women', for instance, and the sometimes disturbingly liberal 'civil, political, religious and business' institutions of the United States (p. vi).

As a disease of modern civilization, neurasthenia would accordingly affect most severely those who were supposedly on its leading edge. Indeed, the kind of work one did was an important component of neurasthenia's aetiology. As Roy Porter (2001: 42) put it, 'American nervousness was a disease of labour', but not the sort performed in a factory or a field. As Beard makes clear, only 'brain-work' counts - the kind of labour that truly drives American progress, continually refines American civilization, and, most importantly, makes America wealthy. It is the heroic ambition, incessant worrying and unceasing labour that so heavily tax the already sensitive nervous systems of these individuals; but it is also, thanks to them, that America enjoys the level of prosperity that it does. As Beard (1881: 97) writes:

All our civilization hangs by a thread; the activity and force of the very few make us what we are as a nation; and if, through degeneracy, the descendants of these few revert to the condition of their not very remote ancestors, all our haughty civilization would be wiped away.

Civilization, in other words, is 'paid for by nervousness' (p. 76) and it is to the nervous that civilization owes its thanks. If, after all, so many of the material spoils seem to go to them, it is rightly so, for, as Beard unapologetically explains (pp. 302-3):

[T] he lower must minister to the higher ... For every brain-worker there must be ten muscle-workers ... that a few thousand might cultivate the intellect, hundreds of thousands must cultivate the soil ... The America of the future, as the America of the present, must be a nation where riches and culture are restricted to the few.

As lopsided as this system is, the alternative is even worse: cultural degeneracy. In the logic of American Nervousness, it is better to be poor in a civilized country than rich in a degenerate one.

What Beard ultimately accomplished in his articulation of the disease is something unexpected and extraordinary in a work which would ostensibly seem to be so narrowly medical and of interest only to a specialized few. $\mathrm{He}$ found a way, through neurasthenia, to lend scientific credence to and provide a biological basis for the social position and political ideologies of the white American upper classes. Neurasthenia was their disease: the exclusive price and privilege of this class and these kinds of people - a 'badge of honor', as it has been called (Lutz, 1991: 275); the sign and province of Fifth Avenue rather than the Five Points. As late as 1917, and well after the disease is supposed to have fallen out of fashion, one writer could still refer to it as a firmly 'aristocratic' disorder (Carroll, 1917: 23), and though Beard never used such 
explicitly elitist terms, neurasthenia was clearly theorized and recognized as a problem of the prosperous.

And yet, without acknowledging the apparent contradiction, Beard would also claim that neurasthenia was broadly 'American'. It was, to be sure, a 'distinguished malady', but it was also something which all Americans should be proud of and, at least implicitly, capable of. Like his theory of the body as dynamo (Beard, 1881: 98-9) or his mathematical expression of the disease's aetiology (p. 176) - with all their ostensible scientific objectivism and universalism - Beard's nationalistic rhetoric seems inclusive and would appear to address itself to a more generally American than exclusively aristocratic audience.

In American Nervousness, Beard's nationalism is evident from preface to postscript. After briefly outlining the disease and summarizing its causes, he veritably gushes (pp. vii-viii):

All this is modern, and originally American; and no age, no country, and no form of civilization, not Greece, nor Rome, nor Spain, nor the Netherlands, in the days of their glory, possessed such maladies. Of all the facts of modern sociology, this rise and growth of functional nervous disease in the northern part of America is one of the most stupendous, complex, and suggestive; to solve it in all its interlacings ... is to solve the problem of sociology itself.

Neurasthenia was thus an American original. It put the country not simply on par with but above the great ancient civilizations, and might even help the world solve its fundamentally human problems. Beard's language is telling here not only for its enthusiasm - 'stupendous', 'marvelous', 'glor[ious]' - but for its imperialism. By invoking Greece and Rome, Beard figured America not simply as a country, but as an empire in which neurasthenia was not just a disease but a 'possession'. For Beard, neurasthenia offered America a way out from underneath the shadow of the Continent, something that 'shall make Europe follow us, instead of our following Europe' (p. xvii). As Beard laments (pp. xvii-xviii):

Long enough this babyland of science has fed on the crumbs that fall from Germany's table; corn and fruits we are carrying to the old country; let new ideas of fresh discoveries go with them. Better to criticise and confirm than be idle; but wiser far to make others criticise and confirm.

The rhetoric is familiar, even if it appears in a most unlikely context: Beard employs neurasthenia to demand and engender national spirit, solidarity and ingenuity on an Emersonian and Whitmanian scale. The very fact of neurasthenia was an index of the nation's glory; its study and dissemination could be America's greatest contribution to human history; and its slow but steady rise may well secure the country's international dominance. As Beard 
imagines it, just as the 'philosophy of Germany has penetrated to all civilized nations', so the 'nervousness of America is extending over Europe, which, in certain countries, at least, is becoming rapidly Americanized' (p. 14). He sees the 'symptoms' of neurasthenia 'invad[ing] Great Britain and the Continent' (p. 57), and he refers to neurasthenics themselves as an 'army of sufferers' (p. 22) as large as that of Russia's standing army - suggesting perhaps that if the symptoms themselves cannot win the metaphorical war he invokes here, America will send a battalion of neurasthenics.

Much more than a simple disease, neurasthenia was a veritable force of Americanization. It was a sign of modernity, a point of national pride and the motor of American empire, and it was upon these grounds that the country's enthusiasm for the disease was most firmly established. As a scientific explanation for sometimes suspicious complaints, it was popular with patients. As a cover-all for a disturbingly incoherent set of symptoms, it was popular with doctors. As a justification of the social status quo and a rationalization of capitalism, it was popular with the country's dominant classes. By figuring the disease as thoroughly and pre-eminently 'American', however, Beard attempted to secure for it an unqualified popularity and by all accounts his efforts were wildly successful. Only a few years after he published American Nervousness, neurasthenia would become known the world over as 'the American disease'. The title of an 1894 McClure's article hailed it as 'the national disease of America' (Wakefield, 1894); Annie Payson Call (1891) referred to it as 'Americanitis'; and even Dana (1904: 341) registered its national importance by noting in supremely facetious but no less telling terms that the disease was one of America's 'most distinctive and precious pathological possessions ... an important stimulus to patriotism and racial solidarity!'.

What we must see here, then, is that ultimately Beard was not just constructing a disease nor even a specifically American disease, but also a particular kind of American. Like other projects of its time and of the coming modernist era, Beard's was a nationalistic one which sought to define what 'America' means and who qualifies as 'American'. Neurasthenia was not only a discourse of disease, but of national identity. It might have been American, but it was hardly democratic, for to be neurasthenic was not simply to be 'sick', but to be white, wealthy, educated, sensitive and refined (and to have come from a long line of such folk). Beard was not brandishing a simple, broad or universalizing sort of nationalism: he was trying to create a particular nation, one identified with and driven by its neurotics. His was one of the many 'nationalisms' being proffered at the time, but it was singular and significant for the way that it articulated a relationship not just between race and nation, but among race, modernity, nation and neurosis - a relationship whose assumptions would be absorbed by the twentieth century's psychoanalytic paradigm and perpetuated long after the disease was supposed to have fallen out of fashion. 


\section{From vogue to rogue: the crisis of neurasthenia in the twentieth century}

Certainly, neurasthenia had its share of detractors from the start. Only five years after Beard published American Nervousness, Sir Andrew Clark, an elite British medical consultant, summarily concluded that:

Neurasthenia is unscientific, inaccurate and misleading ... the descriptions given of it do not include a clear, concise, or distinctive account of genuine nerve exhaustion, and do include a mob of incoherent symptoms borrowed from the most diverse disorder. (quoted in Sengoopta, 2001: 103)

Although Clark's was a rather lonely voice at the time, the criticisms embedded here - that neurasthenia is an essentially overloaded and therefore useless diagnosis - would be resurrected and refined by twentieth-century medical critics of the disease. What was once the source of neurasthenia's value for doctors - that it united a large, confusing and contradictory set of symptoms in a single, authoritative diagnosis - became for many the basis of an attack. Too many doctors, it seems, abused neurasthenia as an easy and convenient diagnosis for whatever they did not understand. The disease devolved into what one doctor called the 'garbage can' of medicine, a sort of 'dumping ground' (Brill, 1930: 123-4) for patients whose symptoms doctors could not competently diagnose or did not want to take the time to understand. Brill recalls one of his medical school teachers remarking that 'whatever puzzles you on the skin you can safely diagnose as eczema and whatever you cannot diagnose on a physical basis you can safely call neurasthenia' (p. 122). This kind of lazy medicine was, in the words of another practitioner, 'bad business' a shirking of responsibility and 'eva[sion] of duty' which heaped dishonour upon more conscientious physicians (quoted in Brill, 1930: 124).

Also, neurasthenia was becoming over-commercialized, ripe for abuse by doctors and institutions who put profits before patients. Dana (1904: 331) took a subtle jab at this neurasthenic 'market' when he noted that if neurasthenia were to disappear, it would no doubt have its 'most tragic effect on the European professors whom our wandering plutocracy consults; and by whom the diagnosis of the "American Disease" is usually made as the patient is announced'. Indeed, sanatoriums, health retreats and private practices on both sides of the Atlantic did a healthy business in nervous disorders and, as Dana suggests here, were only too happy to embrace (and perhaps enable) the American malady. Just as neurasthenia was misused by lazy doctors as a cover for incompetence, so too was it abused by the market as an easy mode of profit. In either case, the bottom line was the same: neurasthenia had become a threat to the profession's integrity.

We find a similar indictment of neurasthenia's commercialization in nonmedical discourse as well. In his short story 'Let Me Feel Your Pulse: Adventures in Neurasthenia', O. Henry (1911: 157-8) describes the sanatorium 
his narrator visits as kind of summer camp for the rich, full of 'turning-lathes, carpenters' outfits, clay-modelling tools ... everything, seemingly, that could interest the paying lunatic guests of a first-rate sanitarium'. Much more a playground than a hospital, Henry's neurasthenic health retreat is the place where the wealthy go not for a cure but for an escape, and the doctors there are only too happy to accommodate them. As Henry repeatedly observes, doctors are quick to diagnose neurasthenia and shuffle their patients off to these retreats (no doubt with an eye towards a kickback), where the staff seems equally uninterested in diagnostic or therapeutic usefulness. After only minutes with the narrator-patient, the physician in charge at the retreat prescribes an absurdly ungrounded, Sisyphisian remedy: 'I think the best mental relaxation for you would be throwing small boulders over the mountainside and then bringing them up again' (p. 158).

This critique of commercialism was elaborated even further in William Taylor Marrs' satirical pseudo-autobiography Confessions of a Neurasthenic (1908). Written from the perspective of a lifelong, 'professional' neurasthenic, the autobiography describes the genesis and adventures of a sufferer, following him from one potential cure to another as he attempts (only ever half-heartedly) to rid himself of the disease. To be sure, the autobiography is a joke, complete with humorous illustrations, and this is perhaps one reason it has received so little attention from historians and scholars. But if we simply dismiss it as a bit of irreverent fun, we miss one of the most fully articulated and important indictments of the disease and those who claimed to suffer from it.

Like O. Henry, Marrs condemns the over-commercialization of the disease. In an unusually humour-free passage, he claims that American health retreats for neurasthenics and other invalids are largely the product not of patients' needs but the economic interests of those who profit from them: the 'land sharks, railroads' and 'hotel and sanitarium people' themselves (Marrs, 1908: 81). The narrator roams the country, hopping from one fashionable retreat to another, ultimately finding not a cure but a con: 'Everywhere I went I saw hundreds of victims being shorn of their money and deriving meager, if any, benefits' (p. 82). Like the druggists who sold watered-down medicine because real drugs 'cost money' (p. 68) or the medical advertisements that promised cures only to 'deceive the sick' and 'take their money' (p. 31), the sanatoriums were just another part of a medical market which itself produced, perpetuated and pilfered neurasthenics.

By no means should we believe, however, that Marrs (or O. Henry) sympathized with swindled sufferers. On the contrary, what seems to distinguish the popular backlash against the disease from the medical one is its focus not so much on neurasthenia, but on neurasthenics. When we examine what evidence we have of the public's understanding of the disease in the early twentieth century, we find it was concerned not so much with the uselessness of neurasthenia as a diagnostic category, or even with the lackadaisical doctors 
who diagnosed it as a matter of convenience, but with the neurasthenics themselves, who, far from Beard's tireless brain-worker, had come to be seen as lazy, self-indulgent opportunists. Because neurasthenia could only ever exist as equal parts discourse and performance - in other words, because it was only legible via patients' words and behaviour - it didn't take people long to realize that it could be appropriated simply by performing it.

The rhetoric became sharper in the twentieth century, when critics voiced a concerted disdain for the neurasthenic's essential laziness. Smith Ely Jeliffe fired a pointed salvo when he claimed of these sufferers that 'Laziness, indifference, weakness of mind and supersensitiveness characterize them all' (quoted in Porter, 2001: 41). He suggests that the cause of their illness is a simple 'lack of moral courage', a subtle reflection, perhaps, of the philosophy of the self-help culture which emerged in the first quarter of the twentieth century. Carroll's The Mastery of Nervousness (1917) was part of this self-help genre, emphasizing the power of the individual to overcome neurasthenia. For him, too, neurasthenics were fundamentally lazy, but also 'shrewd', managing to 'secure periodic vacations, comfortably spent under hospital or sanitarium care, or a long rest at some health resort, through an opportune breakdown of this type' (p. 23).

Almost a decade before Carroll, however, Marrs provided the definitive representation of this sly and indolent neurasthenic in Confessions. Lazy and opportunistic, Marrs' narrator knows how to use medical theory to authorize his laziness. Invoking Beard and then turning him on his head, the narrator claims that because he 'believe[s] in the conservation of energy' (Marrs, 1908: 15), he fears 'working too hard' (p. 24). If the idea is, as Beard put it, to ration one's nerve force, what better way to avoid a breakdown than by never expending any energy at all? Besides, as far as the narrator is concerned, being neurasthenic is a job:

Yes, Webster defines a job as being an undertaking. Neurasthenia is certainly an 'undertaking', therefore it must be a job - a big one at that. It interferes with the holding of any more remunerative job and consumes most of one's time trying to keep his health in a passable condition. (p. 50)

But why, at this point in the disease's history, should there be so much fuss over these perhaps dissembling but otherwise seemingly innocuous types? It must be because lazy neurasthenics represented something more than just an occasion for moral reproach. Indeed, their wilful idleness constituted a threat to a modern America bent on achievement, progress and the triumph of civilization over barbarism. Common to Jeliffe's, Carroll's and Marrs' condemnations of this type is an emphasis on productivity, and Carroll (1917: 23) even euphemizes neurasthenic breakdowns as 'lapses from productiveness'. More than simply morally weak, these neurasthenics were unproductive. Ironically, they undermined that characteristically American 
work ethic that Beard and his contemporaries considered a veritable sign of the neurasthenic.

Perhaps not surprisingly then, we find that this particular criticism of neurasthenia emerges alongside another which assails it as a threat to masculinity. If, as Michael North (2001: 174) claims, one of early modernism's announced targets was 'the ladylike', it is no wonder neurasthenia came under fire. For instance, Marrs (1908: 12) foregrounds the seemingly fundamental effeminacy of neurasthenia by consistently feminizing his male narrator. His neurasthenic notes that as a child, he 'did not engage in the usual sports and rampages of boys', nor did he have any 'boyish ambition to be a cowboy or desperado' (p. 13). The narrator does, however, admit a desire to join the circus: 'Yes, I was going to be an acrobat and wear pretty red tights with glittering spangles!' (p. 14). He twice labels himself 'effeminate' (pp. 27, 35), and in one instance admits to blushing with 'maidenly' shame (p. 92). What Marrs seems to be suggesting, after all, is that male neurasthenics are not just essentially lazy, but essentially feminine and, as such, threaten both the moral and masculine imperatives of (re)production.

Attacks like the ones levelled by Marrs, Jeliffe and others did to some degree diminish neurasthenia's popularity and prestige, but it nevertheless managed to endure long after the height of its own controversy - a controversy which illuminates the ways in which neurasthenia was thoroughly imbricated in modernist anxieties over gender and production, and which suggests that neurasthenia may be, after all, not simply a prelude to but a meaningful component of modernism.

But the neurasthenic crisis of the early twentieth century offers at least one more point to consider. For what seems most remarkable is that nowhere among the various medical and popular challenges to neurasthenia do we find anyone who seems to contest the disease on the ideological grounds upon which Beard formulated it. No one, for instance, questions its exclusive relationship with whiteness or its fundamental association with privilege; no one seems to interrogate the contradiction inherent in an idea which claims to represent American identity while excluding most Americans. No one, in other words, seems to question the essential relationship between race, nation and neurosis that Beard originally proposed. Rather, as the nineteenth century gives way to the twentieth, as soma gives way to psyche, and as Beard gives way to Freud, we find perpetuated over and over again - in scientific treatises, newspapers and dramatic and literary works - the assumption that truly neurotic disorders are the province of the white and privileged. This, we know, is one of the most important prejudices that neurasthenia bequeaths to the modern era, but it is less certain why this prejudice was so readily accepted and circulated. The following section addresses this question, offering a new context for neurasthenia which explains how, by dovetailing with the nineteenth-century's 'insanity question', its prejudices became firmly entrenched in the twentieth century. 


\section{Neurasthenia and the 'insanity question': colour-coding mental disease}

To the catalogue of 'great questions' which preoccupied America in the nineteenth century, scholars and historians have failed to add the insanity question. In broad strokes, I am referring here to a national conversation about and anxiety over the relationship between modernization and mental illness which, in its interrogative form, often sounded something like this: 'Is the number of insane increasing and, if so, is it a function of "civilization"? Depending upon where and how we locate the genesis of this question, it predates the emergence of neurasthenia by decades or centuries. George Rosen (1958: 8) claims that people on both sides of the Atlantic had been asking the question since the eighteenth century, implicitly pinning its emergence to the rise of industrialism. In America, we certainly find suggestions of this concern in the late eighteenth-century writings of Benjamin Rush, but the question seems to take on a new urgency and a decidedly racial tenor in the 1840 s, after the publication in 1841 of the seminal sixth census of the USA. This question was hardly the innocent inquiry of a nation trying to measure and reassure itself in the face of rapid progress and innovation. On the contrary, it was a highly-loaded, highly-racialized reflection of a hyper'civilized' nation's anxiety over its relationship to its uncivilized Other: the so-called 'barbarian' or 'savage', terms which always more specifically signified immigrants, Native Americans and, especially, African Americans, to whom Beard (1881: 189) once referred as the 'bit of barbarism at our door-steps'. I will briefly outline and examine this question to suggest how the discourse of insanity provided fertile ground for Beard's formulation of neurasthenia, and would cooperate with it well into the twentieth century to define the limits of black psychology and adjudicate the relationship between race, modernity, nation and neurosis.

As Edward Jarvis notes in his response to the sixth census of the USA, the report was to serve as something of a watershed in the history of insanity, for while the subject and its statistics had long been important to various parties, there had never been any 'complete and accurate account of the number of these unfortunate sufferers in any country, or race, or class of people'. Accordingly, the 'numerous' investigations of insanity published previously were often contradictory, based as they were on inevitably 'partial' truths (Jarvis, 1844: 71). The sixth census would be the first attempt to gather such numbers on a large and useful scale, and Jarvis summarizes the significance of the undertaking when he observes that a 'wider field than this had never been surveyed for this purpose in any part of the earth, since the world began' (p. 72).

The mandate delivered to the 1840 census marshals suggested an interest in a wide range of disabilities, including deafness, blindness and idiocy, as 
well as insanity. Of particular concern to the government, however, was not just the sheer number of those disabled, but also how those numbers divided along racial lines (predictably, the only races distinguished here were black and white). The mandate itself did not articulate any motive for gathering this information, but if the uses to which the numbers were ultimately put are any indication, the purpose of the census was thoroughly entangled in the politics of slavery.

The insanity statistics published in the sixth census garnered international attention for the single, startling conclusion they suggested: insanity was apparently 'eleven times more frequent for the African in freedom as in slavery' (Jarvis, 1844: 74). This suggestion was remarkable for many reasons, not the least of which was that it contradicted the widespread, long-held primitivist assumption that blacks could never really be insane - one of a number of racial immunity myths which held that blacks were also impervious to the effects of alcohol (Patton, 1911), yellow fever, chorea and prostate cancer (Clark, 1897-98). As J. D. Roberts (1883: 3) says in his study of insanity in the 'colored race', 'It is generally believed that the Negro ... is not as liable to become insane as the more civilized nations'. After all, in a race noted for its 'native cheerfulness and good humor' (O'Malley, 1914: 334) and its naturally 'jolly [and] careless' approach to life (Bevis, 1921: 71), how could there be anything but a consistent and simple sanity?

Yet with no scruples about the way such evidence undermined the primitivist logic upon which American racial relations were based, Southern US writers seized upon the figures as a justification for slavery - a 'new reason for conservatism of the peculiar institutions of the south' (Jarvis, 1844: 74). After all, they insisted, if slavery is over ten-fold more favourable to mental health than freedom, why emancipate? As Jarvis shrewdly realized, the evidence would be twisted into a consolation for slaves, with the South reassuring them that 'although another man's will governs them, yet their minds are not bound with insane delusions, nor crushed in idiocy, as are those of their brethren, who govern themselves' (p. 74).

As it turned out, the 1840 census was egregiously flawed, both statistically and methodologically, and Jarvis (p. 75) exposed it for the 'fallacious and self-condemning document' that it is. After examining the individual returns for each state, Jarvis uncovered some absurd and disturbing inconsistencies. For instance, in Searboro, Maine, where the marshals found no coloured inhabitants, they nonetheless reported six coloured insane. In other towns, every coloured inhabitant was reported to be insane. The census was also methodologically flawed in ways we can well imagine. What, for instance, were the guidelines for defining and recording insanity? How did marshals who, as Jarvis (p. 79) observes, 'obtain their information at second hand, from the reports of others', verify the condition? And why weren't marshals instructed 
to distinguish more clearly 'between the slave and free negro at the south' (p. 82)? For Jarvis (p. 83), it all points towards one conclusion:

[T] he 'sixth census' has contributed nothing to the statistical nosology of the free blacks, and furnished us with no data whereon we may build any theory respecting the liability of humanity, in its different phases and in various outward circumstances, to loss of reason or of the senses.

And yet, despite Jarvis's irrefutable evidence, eloquent arguments, and rather dramatic call for the next Congress to mandate a revision of the document, sloppy census-taking continued long after his report.

Certainly, the story of the sixth census illuminates one of the underexamined grounds upon which slavery was based and upon which abolitionists like Jarvis fought for emancipation, but I rehearse it here not to examine it as another dimension of the slavery discussion, but to suggest it as the starting point of another. For it seems that what the sixth census ultimately sparks is a national discussion about and reconsideration of the relationship between race and insanity that inflects Beard's articulation of neurasthenia and, with it, structures the nation's thinking about race and neurosis well into the twentieth century.

It is hardly a coincidence that interest in the insanity question intensified around the time Beard was articulating his theory of neurasthenia. After all, it was in 1880 - the year Beard wrote American Nervousness and published A Practical Treatise on Nervous Exhaustion - that the US government conducted the tenth census, the results of which would, to an even greater degree than in 1840 , stoke the nation's interest in the relationship between race and insanity. By offering the first set of statistically meaningful post-Civil War figures, the 1880 census allowed observers to compare not just the state of the nation before and after the war but, more specifically, the mental health of blacks before and after slavery - and it was what the figures suggested on this latter point that garnered the most attention and apprehension. In short, the tenth census seemed to document a veritable explosion of insanity among African Americans since the Civil War, with numbers 'fast approximating that of the white population' (Witmer, 1891: 24). While in 1860, the 'colored insane' numbered only 1 in every 5798, by 1880 the figure had risen to 1 in every 1069 (Roberts, 1883: 4-5). The phenomenon spawned a veritable genre of medical journal articles seeking to investigate - and almost always titled 'insanity in the colored race', but the conversation was hardly limited to a small circle of physicians. On the contrary, the question was, according to one writer, of 'vital concern' to social science and all those interested in human development (Mays, 1897: 537), while for another it was one of 'magnitude to the people of the United States' in general (Witmer, 1891:24). Indeed, by 1881 a bill had been introduced in the House of Representatives to investigate the causes of the general increase in insanity, an endeavour which Beard 
himself observed in American Nervousness and which he believed marked 'an advance in the popular interest in one of the great questions of this age or of any age' (Beard, 1881:27).

Yet, while it easy enough to observe with Beard the popularity of the insanity question in the late nineteenth century, it is somewhat harder to account for it. Why did it qualify as one of the age's 'great' questions? What were the motives for asking it? And what kinds of answers were being provided? We find a suggestion of what was at stake in J. M. Buchanan's 1886 study of race and insanity, which begins by observing that for an 'age in which we proudly boast that civilization has reached its acme ... it is an unpleasant thought to consider that this higher development has brought in its train an alarming increase in insanity' (Buchanan, 1886: 1). It is important to note the way this passage positions the discussion of insanity within the context of 'civilization' and a narrative of progress. Insanity here is not simply a dreadful disease, but an indication of advancement; it might be 'unpleasant', but it is also the inevitable, unavoidable function of 'higher development' - the by-product of a culture at its 'acme'. In short, insanity, like the neurasthenia which sometimes precipitated it, ${ }^{4}$ is a sign of civilization and a marker of modernity, and this is why the increase of the disease in the 'colored race' presented such a problem. For if, as Beard (1881: 189) put it, it would be a 'joke' to suggest that African Americans could ever be insane, let alone neurasthenic, and if, after all, insanity was the province of the 'civilized' and a measure of their progress, then how could the number of black insane really approach that of the white? As in 1840, the 1880 census numbers seemingly threatened a fundamental tenet of primitivist logic and one of the distinguishing features of racial identity: a susceptibility to and capacity for the complex neuroses of civilization. Proponents of primitivism needed to account for and contain this apparent contradiction, and they did this by drawing a colour line right through the concept of insanity.

Rather than challenge the results of the 1880 census or question the accuracy of the figures, writers on the insanity question instead worked to establish a difference between black and white mental illness. Roberts (1883: 10-11), for instance, emphasized the disparities in the character of the disease as it appeared in the two races:

As a class the insanity of the Negro appeals to a lower order of feelings; he is more profane; more vulgar; naturally less cleanly than his white neighbor, in insanity his filthiness is almost appalling, and he cares less for the proprieties of life. In fact he seems to approach nearer the brute creation in his insanity ... We do not have to look far for a cause for this difference, when we consider the wide gap there is between the races in reference to refinement, intelligence, accomplishments, social status, etc.

Though Roberts (p. 11) concedes that not 'all colored insane are of a violent, profane and vulgar type', the passage above implies that any other kind would 
be a rare exception. For Roberts, the disparity between the types of insanity experienced by blacks and whites is the product of 'natural' rather than environmental differences: the Negro's biologically-encoded apathy towards hygiene, his inherent disregard for 'proprieties', etc. In these terms, there would seem to be little chance that the 'colored insane' could be anything other than the 'violent, profane and vulgar' sort of lunatics that Roberts describes - a description shot through with the rhetoric and assumptions of primitivism. For Roberts, black insanity is of a 'lower order' which pushes its already uncivilized subject ever closer to 'brute creation', increasing the 'animal propensities' that characterize the race even when sane. Far from a mark of modernity, insanity here serves only to magnify the race's supposed barbarism: it mirrors the race's fundamental coarseness rather than suggests it is approaching (or even capable of) white 'refinement'. Roberts thus ultimately manages to reposition the race within a traditional evolutionist framework and thereby to contain any threat to primitivist logic posed by the census numbers. Black insanity - like the race itself - is reassuringly of a 'lower order', which suggests not that the race is advancing, but devolving ever further towards 'brute creation'. The incidence of black insanity might be fast approximating that of the white population, but the race cannot claim it, as whites do, as a sign of 'higher development' (p. 11).

Just as the character of insanity differed along the colour line, so did the mode of its acquisition. In other words, how one became insane was just as important as the character of the insanity itself. Indeed, every article on 'insanity in the colored race' demonstrates a marked concern with the disease's aetiology, and the parity between these accounts is astonishing. For all these writers, the root cause of black insanity is the same: the freedom granted by emancipation. Most of these texts feature some sort of 'common sense' claim that prewar insanity among blacks was virtually non-existent. Buchanan (1886: 2), for instance, bluntly insists that 'any slave-owner will tell you that insanity among the negroes was a rare occurrence before the war; Witmer (1891: 19) offers that 'many intelligent people' have told him that 'while they had known of colored idiots and epileptics before the war, they never had heard of an insane colored person'; and Mays (1897: 537-8) cites no less than eight medical authorities who all testify to the absence of insanity under slavery.

Yet, how could freedom so seriously jeopardize black sanity while slavery, with all of its well-documented horrors and abuses, apparently preserve it? As J. F. Miller explains in his 1896 study:

The negro in slavery had 'no thought for the morrow', wherewithal he should be fed and clothed. Nor did the claims of family press upon him to worry and affect his mind; no ambitious hopes stirred his brain as to the possibilities of his future; but 'far from the madding crowd's ignoble strife' he spent his quiet, humble life in his little log cabin, with his master to care for every want of self and family, in sickness and in health. 
It is an undisputed fact, known to our Southern people, that no race of men ever lived under better hygienic restraints ... Freedom came to him, and a change came over his entire life. (quoted in Mays, 1897: 539)

This passage, with its appalling lack of awareness, is typical of the genre for its nostalgic sentimentalism and its suggestion that blacks were never insane before the war for the same reason that children never are: they were wholly guarded and provided for, living ever in the present, free of the strains and strife suffered by their civilized betters. Freedom forced former slaves to confront 'civilization' which, according to Miller's logic, made demands 'upon the negro which his intellectual parts were unable to discharge' (Mays, 1897: 539). Black insanity in this sense is the product of limited mental capacity a mind unfit for civilization. Mays (p. 539) puts a finer point on it when he writes that '[i]f we fully realize that the negro came out of the darkness of Egypt and was brought face to face with a civilization ... it cannot surprise any one that in many instances he is unequal to the task of adjusting himself ... and falls a prey to disease'. In both cases, we see how the explosion of black insanity since emancipation can be explained in terms coherent with primitivist logic: it is just another sign of the race's cultural inferiority and its incompatibility with modern American civilization.

Of course, it is not the strain of freedom alone that produces black insanity, but what the race chooses to do with its freedom. After all, even whites are susceptible to the stresses of civilization and the pressures of freedom, and to suggest a common aetiology for insanity in both races would undermine any effort to distinguish its colour line. Fittingly, then, we find black insanity figured not really as the consequence of civilization, but of a biological propensity towards licentiousness which, though carefully guarded under slavery, finds full expression in freedom. As Buchanan (1886: 4) makes clear:

This sudden striking the shackles from his hands gave him not only freedom from the care and surveillance of his master, but it gave him liberty which he converted into license to violate and outrage all the natural and moral laws provided for his well-being.

Notice how and where Buchanan locates the blame for black insanity. The disease is not simply the result of emancipation or an effect of liberty. Rather, the Civil War granted the slave freedom, but then he 'converted it' to licentiousness, choosing to 'violate' the laws of nature and morality by overindulging base appetites. This is not the sort of insanity found in the white race which is so often figured in compassionate neurasthenic terms as the result of a refined and sensitive nervous system overburdened by the pressures and responsibilities of civilization. Black insanity is not a noble neurosis nor, indeed, a neurosis at all. It is, in Buchanan's terms, more akin to a wage of sin, an idiom which lifts the burden of responsibility for the disease from the shoulders of the abstract forces of 'civilization' and transfers 
it to black individuals themselves. In these terms, black insanity is as much the result of a moral as a constitutional weakness.

We see, then, how these writers managed to figure black insanity as both a product and a reflection of the race's evolutionary status: it is, as Roberts originally put it, a 'lower order' disease for a supposedly lower order of people a timely reassurance of the race's biological and cultural inferiority for a Reconstruction-era America increasingly anxious about its racial identity. By proposing a different character and aetiology for insanity in the coloured race, these writers drew a vivid colour line through the disease, thereby defusing one of the threats posed by the post-emancipation explosion of black insanity. The higher incidence of the disease did not, after all, suggest that blacks were susceptible in the same way or to the same kinds of mental illness, nor were they in any way approaching a level of civilization occupied exclusively by whites. On the contrary, and in the spirit of Beard's construction of neurasthenia, the reconfiguration of insanity along racial lines demonstrated that blacks were in no way privy to or even capable of the refined and complex mental illnesses of civilization.

Neurasthenia and insanity are thus similar in more ways than one, and what I want to highlight here is how these two discourses, emerging at around the same time, employing the same biological logic and manifesting the same primitivist assumptions, cooperated to manufacture a particular kind of American whose identity and modernity were fundamentally predicated upon a capacity (or lack thereof) for complex, modern neuroses. Like neurasthenia, the discourse of insanity worked to coordinate race, modernity and mental illness to establish a particular and exclusive definition of national identity which disqualified a majority of the population. And, like neurasthenia or perhaps because of it - the insanity question never really went away. Well into the twentieth century, and right in the thick of modernism, major medical journals were still publishing articles which investigated long-familiar topics. Mary O'Malley's 1914 study of 'Psychoses in the colored race', for instance, kept alive the 'discussion of the relative proportion of the increase in mental disease in the colored population as compared with the white' (p. 310), while W. M. Bevis's 1921 'Psychological traits of the Southern Negro' worked to maintain insanity's colour line. Certainly, the question we now must ask is how this particular version of national identity - this modern, American neurotic subjectivity so powerfully articulated and popularized by Beard and reinforced by the discourse of insanity - continued to evolve in the early twentieth century. More specifically, future research should focus on the reactions of those to whom this identity was so strenuously denied; how did they acknowledge and respond to it, resist or accept it, negotiate or appropriate it? We must, in other words, ask how mental illnesses of all kinds and degrees continued to shape the meaning of 'American'. 


\section{Notes}

1. Here and throughout this paper, 'America' refers specifically to the USA.

2. The history of 'neurasthenia' is even more tangled than most scholars of the disease suggest. After claiming it as his own in 1869, Beard was scolded by the American fournal of Insanity for overlooking E. H. Van Deusen's introduction of the term in 1867 (see Sukov, 1971). Seventy years later, historian Henry Alden Bunker found an even earlier use of the term in an 1856 medical lexicon (Bunker, 1944). Most scholars accept Bunker's word as final (see, e.g., MacMillan, 1976; Rosenberg, 1962; Sicherman, 1977; Sukov, 1971; Wiener, 1956), but my own research suggests an even earlier origin, in the 1833 edition of Dunglison's Medical Dictionary - a point first suggested by Margaret Cleaves (1886: 164) in her study of neurasthenia in women.

3. I say 'primarily' because, while Beard certainly recognized the potential for and occurrence of neurasthenia in women, he nonetheless, like most other neurologists of his time, considered men 'peculiarly liable' to the disease because of the particular kind of labour or 'brain work' they performed (see also, for instance: Collins and Phillips, 1899: 413; Jewell, 1881:22). Freud also considered neurasthenia to be more prevalent in men, though for different reasons: for him, it was a function of their greater penchant for masturbation (MacMillan, 1976: 383). The gender of neurasthenia is something scholars continue to debate; see: Briggs, 2000: 247; Gijswijt-Hofstra and Porter, 2001: 23; Gosling, 1987: 34.

4. As Beard and others suggested, insanity could be a 'sequence' or final effect of neurasthenia (see: Beard, 1881: 16, 59; Cowles, 1891: 8, 54).

\section{References}

Armitage, D. (1929) A Challenge to Neurasthenia (London: Williams and Norgate).

Beard, G. (1869) Neurasthenia, or nervous exhaustion. The Boston Medical and Surgical fournal, 3, 217-221.

Beard, G. (1880) A Practical Treatise on Nervous Exhaustion (Neurasthenia): Its Symptoms, Nature, Sequences, Treatment (reprinted New York: Kraus Reprint Co., 1971).

Beard, G. (1881) American Nervousness: Its Causes and Consequences (New York: Putnam).

Bevis, W. (1921) Psychological traits of the Southern Negro with observations as to some of his psychoses. American fournal of Psychiatry, 78, 69-78.

Briggs, L. (2000) The race of hysteria: 'overcivilization' and the 'savage' woman in late nineteenth-century obstetrics and gynecology. American Quarterly, 52(2), 246-73.

Brill, A. (1930) Diagnostic errors in neurasthenia. Medical Review of Reviews, 36, 122-9.

Buchanan, J. (1886) Insanity in the Colored Race (Meridian: John J. Dements).

Bunker, H. A. (1944) American psychiatric literature during the past one hundred years. In J. Hall (ed.), One Hundred Years of American Psychiatry (New York: Columbia University Press), 195-272.

Call, A. P. (1891) Power Through Repose (New York: Roberts Brothers).

Carroll, R. (1917) The Mastery of Nervousness Based Upon Self Reeducation (New York: The MacMillan Company).

Clark, G. (1897-98) The immunity of the Negro race to certain diseases and the causes thereof. Maryland Medical fournal, 38, 222-4.

Cleaves, M. (1886) Neurasthenia and its relation to diseases of women. Transactions of the Iowa State Medical and Chirurgical Society, 7, 164-79.

Collins, J. and Phillips, C. (1899) The etiology and treatment of neurasthenia: an analysis of three hundred and thirty-three cases. Medical Record, 55, 413-21.

Cowles, E. (1891) The Shattuck Lecture: Neurasthenia and its Mental Symptoms (Boston: David Clapp and Sons). 
Dana, C. (1904) The partial passing of neurasthenia. Boston Medical and Surgical fournal, $150,339-44$.

Feigenbaum, D. (1930) Editor's note. Medical Review of Reviews, 36, 106.

Gijswijt-Hofstra, M. and Porter, R. (eds) (2001) Cultures of Neurasthenia from Beard to the First World War (New York: Rodopi).

Gosling, F. (1987) Before Freud: Neurasthenia and the American Medical Community, 1870-1910 (Urbana: University of Illinois Press).

Henry, O. (1911) Let me feel your pulse: adventures in neurasthenia. In O. Henry, Sixes and Sevens (New York: Doubleday, Page \& Co.), 145-62.

Hyman, R. (1998) Territories of the Self: Nervous Disease and the Social Logic of PreFreudian Subjectivity. Unpublished dissertation, University of Virginia.

Jarvis, E. (1844) Insanity among the coloured population of the Free States. American fournal of Medical Science, 7, 71-83.

Jewell, J. (1881) Influence of our present civilization in the production of nervous and mental diseases. Fournal of Nervous and Mental Disease, 8(1), 1-24.

Lutz, T. (1991) American Nervousness, 1903: An Anecdotal History (Ithaca: Cornell University Press).

Lutz, T. (2001) Varieties of medical experience: doctors, patients, psyche and soma in America. In M. Gijswijt-Hofstra and R. Porter (eds), Cultures of Neurasthenia from Beard to the First World War (New York: Rodopi), 51-70.

Macmillan, M. (1976) Beard's concept of neurasthenia and Freud's concept of the actual neuroses. Fournal of the History of the Behavioral Sciences, 12(4), 376-90.

Marrs, W. (1908) Confessions of a Neurasthenic (Philadelphia: F. A. Davis Company).

Mays, T. (1897) Increase of insanity and consumption among Negro populations of the South since the war. Boston Medical and Surgical fournal, 136, 537-40.

North, M. (2001) Reading 1922: A Return to the Scene of the Modern (New York: Oxford University Press).

O'Malley, M. (1914) Psychoses in the colored race: a study in comparative psychiatry. American fournal of Insanity, 71, 309-37.

Patton, G. (1911) The relative immunity of the Negro to alcoholism. New Orleans Medical and Surgical fournal, 64, 201-9.

Porter, R. (2001) Nervousness, eighteenth and nineteenth century style: from luxury to labour. In M. Gijswijt-Hofstra and R. Porter (eds), Cultures of Neurasthenia from Beard to the First World War (New York: Rodopi), 31-42.

Roberts, J. D. (1883) Insanity in the Colored Race (Goldsboro, North Carolina: Argus Job Print); originally published in North Carolina Medical fournal, 12.

Rosen, G. (1958) Social stress and mental disease from the eighteenth century to the present: some origins of social psychiatry. The Milbank Memorial Fund Quarterly, 37(1), 5-32.

Rosenberg, C. (1962) The place of George M. Beard in nineteenth-century psychiatry. Bulletin of the History of Medicine, 36, 245-59.

Sengoopta, C. (2001) 'A mob of incoherent symptoms'? Neurasthenia in British medical discourse, 1860-1920. In M. Gijswijt-Hofstra and R. Porter (eds), Cultures of Neurasthenia from Beard to the First World War (New York: Rodopi), 97-115.

Sicherman, B. (1977) The uses of diagnosis: doctors, patients, and neurasthenia. fournal of the History of Medicine, 32, 33-54.

Sukov, M. (1971) Introduction [to reprint ed.]. In G. Beard, A Practical Treatise on Nervous Exhaustion (Neurasthenia): Its Symptoms, Nature, Sequences, Treatment [1880] (New York: Kraus Reprint Co.).

Van Deusen, E. H. (1869) Observations on a form of nervous prostration, (neurasthenia,) culminating in insanity. American fournal of Insanity, 25, 445-61. 
Wakefield, E. (1894) Nervousness: the national disease of America. McClure's Magazine (New York), 2, 302-7.

Wiener, P. (1956) G. M. Beard and Freud on 'American nervousness'. Fournal of the History of Ideas, 17, 269-74.

Witmer, A. (1891) Insanity in the colored race in the United States. Alienist and Neurologist, $12,19-30$. 